\title{
The Cellular Architecture of the Primo Vascular System
}

\author{
Fatma El-Zahraa A. Mustafa* \\ Department of Anatomy and Histology, Faculty of Vet. Medicine, Assiut University, Assiut, Egypt
}

Received June 15, 2021

Revised November 3, 2021

Accepted December 6, 2021

Correspondence to

Fatma El-Zahraa A. Mustafa

Department of Anatomy and Histology,

Faculty of Vet. Medicine, Assiut

University, Assiut, Egypt

E-mail f.histology@aun.edu.eg
The primo vascular system (PVS) is of great interest to scientists in the last few years The PVS plays a role in stem cell migration, immune function, erythropoiesis, tissue regeneration, and cancer metastasis. Discovered by Bong Han Kim in 1960, the PVS was described as a new, independent system that is distributed in the body of different animals. Since then, several cells have been discovered as important constituents of the PVS. Endothelial cells are hallmarks for the identification of the PVS, as they line the sinuses of the primo vessels and are characterized by their arrangement of rod-shaped nuclei in a parallel, broken-line fashion along the primo vessels. Immune cells as mast cells, eosinophils, neutrophils, and lymphocytes are also hallmarks for the identification of the PVS. One of the most interesting cells in the PVS are p-microcells. Primo nodes are a stem cell niche due to their p-microcells content, which express stem cell biomarkers CD133 and Oct 4. Mature erythrocytes and hematopoietic stem cells have also been observed in the PVS. Hematopoietic stem cells were observed in the PVS. Hematopoietic Stem Cells are the source of the cellular component of blood. Additionally, adrenaline and noradrenaline-producing cells, mesothelial cells, and smooth-muscle-like cells have also been described in the PVS.

Keywords: Immune cells, Chromaffin cells, P-microcells, Erythrocytes, Telocyte

\section{INTRODUCTION}

The primo-vascular system (PVS) is of great interest to scientists in the last few years. The PVS was first described by Bong Han Kim in 1960 as a new independent system that is distributed in the body of different animals [1]. This newly discovered anatomical system is made up of primo vessels that connect primo nodes [2]. Primo vessels are made up of primo sub-vessels that enter the primo node and branch out (Fig. 1A) [3,4].

The PVS is classified according to location as superficial and deep. Superficial PVS nodes are located in the skin. Deep PVS nodes are located at different points intravascularly (inside the blood vessels, and lymphatic vessels), extravascular (run along but outside the blood vessel and lymphatic vessels), on organ surfaces (floating on the surfaces of the visceral organs), in intra-organs (inside visceral organs), and in the nervous system (floating in cerebrospinal fluid) [4-6]. Several functions have been described for the PVS system in regards to health and disease, including as a stem cell migration route, erythropoiesis, immune function, tissue regeneration, and play a role in cancer metastasis [7].

Several cells have been discovered as important constituents of the PVS system, including mesothelial cells, endothelial cells, smooth-muscle-like cells, immune cells, erythrocytes, chromaffin cells, and p-microcells. This review will discuss the role that each of these cells play in the PVS, and then briefly discuss directions for future research.

\section{MESOTHELIAL CELLS}

Several authors have described the epithelial cells covering the PVS, but the most interesting point obtained by Lim et al., (2020) [8] which described these cells as mesothelial cells covering the surface of the primo vessels and primo nodes collected from the surface of rat abdominal organs; specifically, as a single layer of flat cells with flat nuclei. These mesothelial cells were studied using Harris's haematoxylin and eosin staining and were then confirmed by scanning electron microscope and selective biomarker immunostaining for mesothelial cells HBME-1 (hector battifora mesothelial-1). Mesothelial cells provide non-adhesive, slippery, and protective surfaces to facilitate the movement of visceral organs. In addition, mesothelial cells protect tissues from infection, abrasion, have the ability to convert cells into smooth muscle fiber, regulate tissue repair, are involved in the 

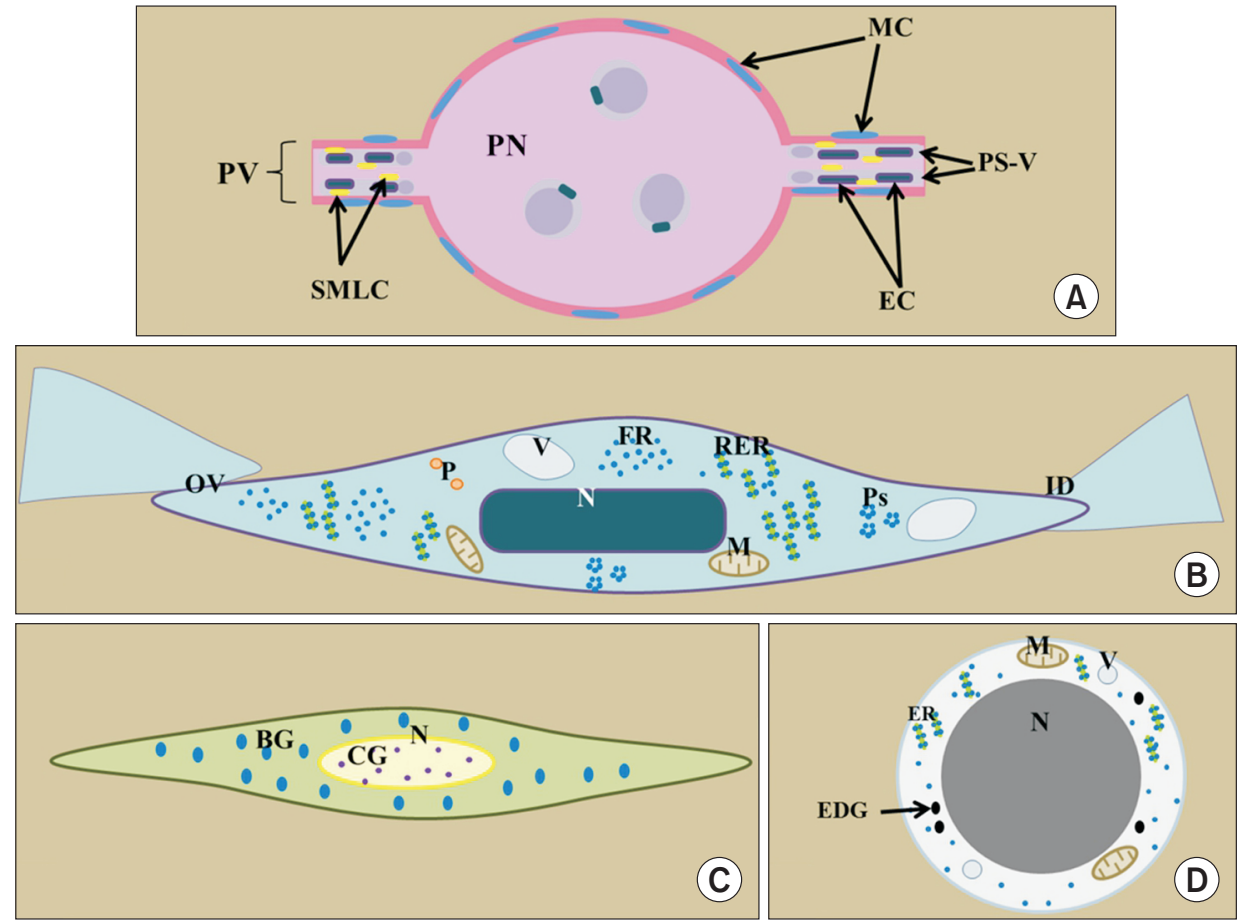

Fig. 1. Schematic diagram. (A) The primo node and primo vessel. (B) Ultrastructure of the primo-vascular system endothelial cell. (C) Ultrastructure of the primo vascular system Smooth muscle-like cells. (D) Ultrastructure of the primovascular system P-microcell. Primo node (PN), primo vessel (PV), primo sub-vessels (PS-V), mesothelial cells (MC), Endothelial cells (EC), Smooth muscle-like cells (SMLC), rough endoplasmic reticulum (RER), free ribosomes (FR), polysomes (Ps), vacuoles (V), cytoplasmic edges interdigitation (ID), cytoplasmic edges overlapping (OV), pinocytotic vesicles (P), mitochondria (M), nucleus $(\mathrm{N})$. cytoplasmic fine basophilic granules (BG), fine chromatin granules (CG), endoplasmic reticulum (ER), and electron-dens small granules (EDG).

immune response, and play a role in cancer distribution and restriction (Fig. 1A, 2) [9].

\section{ENDOTHELIAL CELLS}

Endothelial cells are considered as one of the hallmarks for the identification of the PVS [10]. Endothelial cells line the sinuses of the primo vessels. Specifically, each sinus (small ductile) is lined with a single, non-fenestrated endothelial cell $[6,11]$. The nuclei of these endothelial cells are rod-shaped and arranged in parallel, broken-line fashion along the primo vessel (Fig. 1A, 2) [12-14]. The primo vessel provides a positive expression for the endothelial cell marker von Willebrand factor (vWF); however, the primo vessel provides a negative expression to the blood vessels endothelial cell marker, CD31. Also, negative expression was observed in the primo vessels for the lymph vessel, endothelial cell marker, LYVE-1. This indicates that the primo vessel endothelium differs from those of the blood vessels and lymph vessels [11].

Ultrastructurally, endothelial cells contain well-developed, rough endoplasmic reticulum, free ribosomes, polysomes, large vacuoles, and interdigitation or overlapping of the cytoplasmic edges. Endothelial cells of the PVS are differentiated from those of the blood and lymph vessels by the small amount of pinocytotic vesicles they contain, with no intercellular adherens junctions (as desmosome) or tight junctions (Fig. 1B) [15].

\section{SMOOTH MUSCLE-LIKE CELLS}

Smooth muscle-like cells are observed at the outer membrane of the primo sub-vessels. These cells are elongated, spindle or oval-shaped, and have elliptical nuclei. In addition, fine basophilic granules are distributed in the cytoplasm and the nuclei are characterized by fine chromatin granules (Fig. 1A, C, 2) $[4,5,16]$. The outer layer of the superficial primo node is described as a smooth muscle layer that helps secretion move toward the primo vessels and helps primo fluid circulation [17].

\section{IMMUNE CELLS}

Primo vessels and primo nodes are densely packed with different immune cells, such as white blood cells and mast cells. These cells are considered as one of the hallmarks for PVS identification. Different kinds of cells can be clearly 
identified as mast cells, eosinophils, neutrophils, monocytes, macrophages, lymphocytes, and plasma cells $[10,14,15,18]$. Normally the major hematopoietic organ was the bone marrow. Hematopoietic stem cells are the source of the cellular component of blood, and have been observed at various stages of differentiation on the primo node, thus indicating that hematopoietic activity also occurs within the primo nodes [4]. The numerous immune cells found in the PVS indicate the important role it plays in the immunological function of an organism [18].

\section{Mast cells}

One of the cellular constituents of the PVS isolated from the organ surface of rats are mast cells (3.8\%) (Fig. 2). These cells are classified according to their morphology into typical (10-15 $\mu \mathrm{m})$, large (> $20 \mu \mathrm{m})$, and elliptical mast cells. Typical mast cells contain closely packed granules and centrally located nuclei. Elliptical mast cells were more numerous observed in the primo vessels than in the primo nodes. The granules of these cells are about $1 \mu \mathrm{m}$, with cells observed at different stages of degranulation [18]. Mast cells were also observed on the primo nodes of rat hearts, with some of these cells degranulating on the pericardium and epicardium. These findings indicate that the PVS plays a role in direct blood pressure modulation [19]. The mast cells of the PVS are similar to the mast cells that have been observed in the connective tissue of rodents, which is characterized by their large size and granules with metachromatic staining when using toluidine blue stain, a common stain for mast cells $[10,18,20,21]$.

Mast cells are immune cells found in connective tissue throughout the body. The degranulation of mast cells modulates many physiological and pathological actions, such as angiogenesis and tissue repair [21]. Mast cells release histamine and are considered a mediator for allergy reactions. In addition, renin is observed on mast cells, which acts as a blood-pressure-modulating hormone [19]. Mast cells play a role in the functional regulation of certain cells, such as lymphocytes, dendritic cells, macrophages, eosinophils, epithelial cells, and endothelial cells. The mast cell content of the PVS indicates that the system plays a role in the innate immune response, since mast cells are important to innate immune function $[10,22,23]$.

\section{Eosinophils}

Eosinophils, which are identified by bi-lobed nuclei and large cytoplasmic eosinophilic granules, were observed in the PVS obtained from the organ surfaces of rats, and were confirmed with a transmission electron microscope (Fig. 2) $[18,24]$. Eosinophil is considered a multifunctional cell that plays a role in the regulation of innate and adaptive immune responses. Eosinophils play a role in hypersensitivity mechanisms, protection from parasitic infection, cytokine production, and the mediation of tissue homeostasis $[25,26]$.

\section{Neutrophil}

Neutrophils with unstained granules and multilobed nuclei were also detected in the PVS obtained from the surface of the internal organs of rats (Fig. 2) [18]. Neutrophils are phagocytic cells that play a key role in the innate immune response and the elimination of pathogens. Neutrophils are important in the phagocytosis, killing, and digestion of microorganisms,

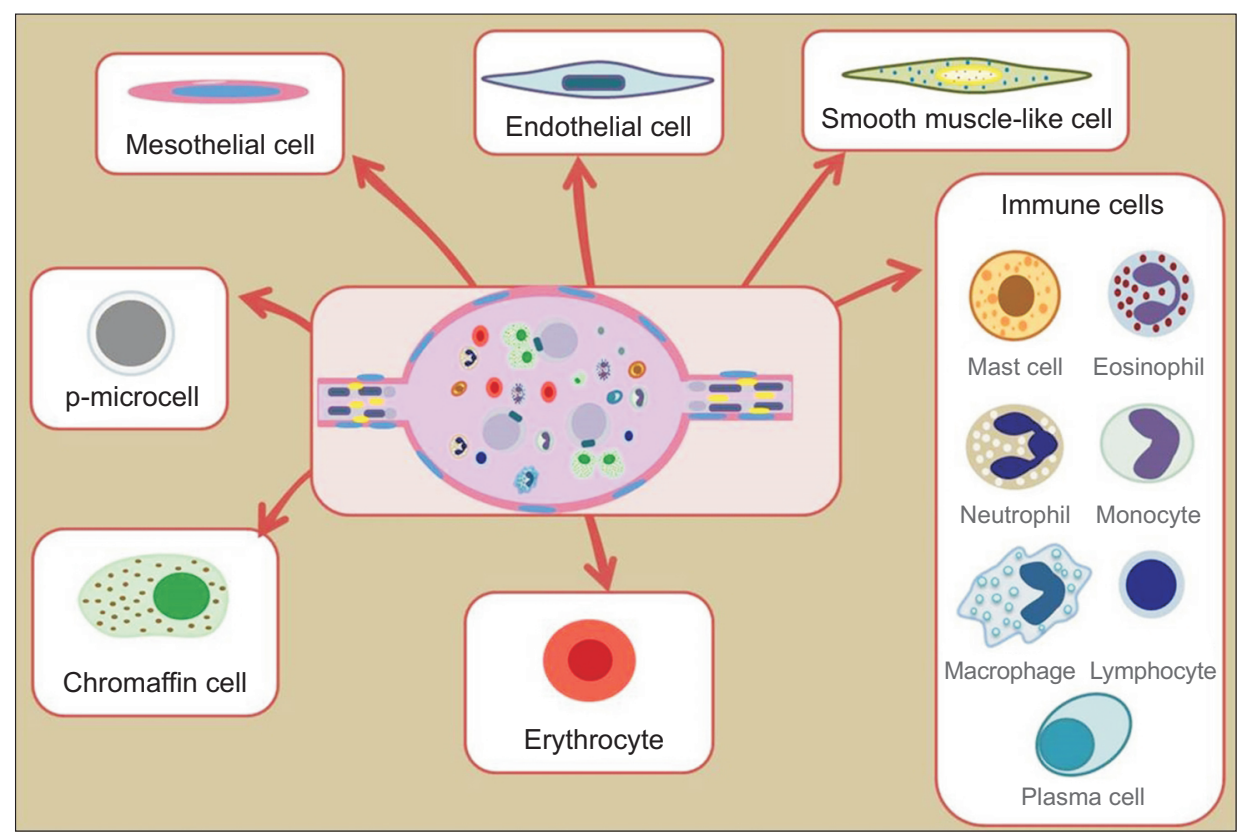

Fig. 2. Schematic diagram showing the Summary of the cellular architecture of the primovascular system. 
and in the phagocytosis and digestion of dead cells [26].

\section{Monocytes}

Monocytes are phagocytic cells that are part of the innate immune system and are antigen-presenting cells. In addition, monocytes have the ability to kill microorganisms [26]. Monocytes with their characteristic kidney-shaped nuclei, were observed in the PVS isolated from the surfaces of rat organs found in the peritoneal cavity; the cells were stained with toluidine blue and confirmed with a transmission electron microscope (Fig. 2) [24].

\section{Macrophages}

The toluidine blue-stained PVS obtained from organ surfaces in the peritoneal cavity of rats also contained macrophages, with the transmission electron microscope revealing phagosomes within the macrophages (Fig. 2) [24]. The monocyte-macrophage cell line is a key player in the host defense system [27]. Macrophages show a great functional diversity and are present all over the body. In addition, macrophages play a role in immunity, tissue repair, and homeostasis [28].

\section{Lymphocytes}

Lymphocytes with dense-staining nuclei and only a small amount of cytoplasm were observed in the PVS obtained from rabbit placenta and the surfaces of the internal organs of rats (Fig. 2) [14,18]. Lymphocytes are very important in the immune response and body's defense against pathogens. The major role of lymphocytes is to produce adaptive immune responses after subjection to new antigens and to form a memory of such antigens [29].

\section{Plasma cells}

Plasma cells are important cells detected in the PVS (Fig. 2), and were found in the PVS of the surface organs of rats [18]. Plasma cells are the last differentiation stage of mature B lymphocytes and are key players in humoral immunity, due to the number of antibodies they secrete and their prolonged lifespan [30].

\section{ERYTHROCYTES}

Mature, normal RBCs with their characteristic shape as non-nucleated, biconcave disks were observed in the PVS obtained from the surface of the internal organs of rats (Fig. 2) [18]. Moreover, the primo nodes and primo vessels in rats with heart failure showed significant erythropoiesis [31]. The major function of RBCs is to transport oxygen from the lungs to the tissues. Additionally, RBCs play a minor role in carbon dioxide transport from the periphery to the lungs and in local blood flow regulation. Erythropoiesis is normally produced in the bone marrow and is derived from haemopoietic stem cells [26].

\section{CHROMAFFIN CELLS}

Chromaffin cells were observed in small groups in the primo nodes close to the sinuses (Fig. 2) [4]. These cells displayed a positive reaction to chromogranin in rat primo nodes [32]. Adrenaline and noradrenaline-producing cells and -storing cells were found in the primo node of rabbits, with the hormones confirmed using the ELISA method. Adrenaline and noradrenaline are produced by the same cell, which is oval-shaped and is distributed singly or in small clusters at the central area of the primo node $[33,34]$. The concentrations of adrenaline were greater than that of noradrenaline in the rabbit PVS; however, greater noradrenaline concentrations were found in the adrenal gland, which is one of the main sources of circulating catecholamines in the body. In contrast, the greatest adrenaline concentration was observed during rat gestation in the adrenal medulla [34].

Catecholamines are responsible for blood pressure regulation by contracting the vascular smooth muscle and cardiac muscle, although catecholamines induce smooth muscle relaxation in the gastrointestinal tract, bronchioles, and urinary tract. Both Adrenalin and noradrenaline regulate metabolism by increasing blood glucose levels through the induction of glycogenolysis in the liver, elevated glucagon secretion, reduced insulin secretion from the pancreas, and adipose tissue lipolysis. Noradrenaline is important in the maintenance of cognitive processes, such as attention, perception, memory consolidation, and learning. In type I hypersensitivity reactions, adrenalin inhibits mediator release from mast cells and basophils [35,36].

\section{P-MICROCELLS}

Primo nodes are considered a stem cell niche due to their p-microcells content. The maturation and distribution of these cells occurs in the PVS. A single p-microcell can give multiple p-microcells and either blood cells. The proliferation of p-microcells results in clusters of daughter cells and the cells of the same cluster fuse to form one large mature p-microcell. P-microcell budding has also been described as the first step of proliferation. Some cells showed budding or a thread-like structure when cultured, which resulted in new daughter cells that help transfer molecules as microvesicles and provide polarized tension to support various biological processes, such as asymmetrical differentiation or migration. Stem cell biomarkers, such as CD133, Nanog, and Oct 4, 
are expressed in p-microcells. P-microcells have the same character as stem cells, as they proliferate under an artificial state and play a role in tissue regeneration. Stem cells regulate the homeostasis of tissues through cell renewal [4,37-39].

P-microcells are 1-4 $\mu \mathrm{m}$ in diameter, and are rounded, oval, or irregular in shape, with a smooth cell membrane that sometimes with processes and displays cytoplasmic budshaped projections. The cytoplasm contained well-developed endoplasmic reticulum, mitochondria, vacuoles, and electron-dense, small granules. In addition, each cell contains one or two deeply stained nuclei with wrinkled nuclear membranes and abundant chromatin. Adjacent cells may also be connected to p-microcells through cytoplasmic processes (Fig. 1D-2) $[4,6,39,40]$.

\section{CONCLUDING REMARKS AND FUTURE RESEARCH}

\section{Conclusions}

According to previous published works several important cells have been described as part of constituents of the PVS. Endothelial cells which line the sinuses of the primo vessels and its nuclei arranged along the primo vessels in a parallel, broken-line fashion. Immune cells as mast cells, lymphocytes, neutrophils, eosinophils, and plasma cells are also identified in the PVS. In addition, p-microcells which described as stem cells and express stem cell biomarkers Oct 4 and CD133. Hematopoietic stem cells which the source of the cellular component of blood and mature erythrocytes have also been demonstrated in the PVS. In addition, adrenaline and noradrenaline-producing cells, smooth-muscle-like cells, and mesothelial cells have been described in the PVS.

\section{Future researches}

\section{1) PVS and cupping (Al-Hijamah prophetic medicine)}

Despite its very long history of use, acupuncture remains not well understood, despite its increasing worldwide acceptance as an effective treatment option [2]. A relationship between the PVS and acupuncture meridians has been described $[10,41,42]$. Also, some cupping points were described as part of the meridian acupoints system [43]. The idea of PVS relation to acupuncture meridians must induce scientists to study the relationship between the PVS and cupping (Al-Hijamah) which is one of the most ancient, effective treatments and is recommended as prophetic medicine.

\section{2) The specificity of the cellular architecture of the PVS}

Additional study of the cellular architecture specificity in the PVS at different sites is needed. Such study will add to our knowledge of the subtypes and functions of the PVS. For example, RBCs were not observed in the PVS of some internal organs of rabbits and rabbit placenta [14,15]. Similarly, mast cell densities are greater on the organ surface PVS than in the subcutaneous PVS, but the degranulation ratio was greater in the subcutaneous PVS than the organ surface PVS [10].

\section{3) Newly discovered cells as telocyte and the PVS}

Further study is needed to identify the relationship between various newly discovered cells, such as telocyte and the PVS. Telocytes are associated with the vascular, nerve, immune, and endocrine systems [44]. In addition, telocytes have been found at different body parts of human and different animals [45-55]. Telocytes consist of a cell body and telopodes which long cytoplasmic extensions. These cells contact each other (homo-cellular contacts) or contact with different types of cells as macrophages, mast cells, and fibroblasts (hetero-cellular contacts). Telocytes can regulate tissue regeneration, stem cell function, and homeostatic processes, and are also involved in immunological surveillance. Information can be transferred from telocyte to neighboring cells or non-neighboring cells via the release of extracellular vesicles $[45,55]$. Telopodes form a complicated network in the connective tissue of different body regions and can also connect the skin to different organs telocytes are hypothesized to be essential cells in Chinese Traditional Medicine meridians due to their ability to connect different connective tissue structural components throughout the body [44]. Moreover, Telocyte-like cells were described in the rabbit vagina recently [56].

\section{4) PVS and cancer research}

PVS is located around and within tumors and is a route for cancer metastasis. Metastasis is a major problem in cancer patient treatment, and occurs via the lymphatic system, blood vessels, or within body cavities. Cancer cells that spread from the original superficial tumor to inside the abdominal cavity are carried by the PVS. Tumor cell migration via the primo vessel is more efficient than the lymphatic system. Cancer induces dense PVS formation near tumors, resulting in increased numbers of primo nodes and primo vessels with tumor development [57-62]. Thus, the PVS may play a role in cancer diagnosis and control, which requires further studies $[57,61]$.

\section{ACKNOWLEDGEMENTS}

The author thanks Dr. Sayed, Y.A., the lecturer of soils and water, Faculty of Agriculture., Al-Azhar Univ., Assuit, Egypt, for his cooperation and advice. 


\section{CONFLICT OF INTEREST}

The author declares no conflict of interest.

\section{ORCID}

Fatma El-Zahraa A. Mustafa, https://orcid.org/0000-0001-5600-8712

\section{REFERENCES}

1. Lee BC. Evidence for novel tubular-bundle structures entangled in the fascia of the inner abdominal wall of a rat. Micron 2019; 123:102681.

2. Soh KS. Bonghan circulatory system as an extension of acupuncture meridians. J Acupunct Meridian Stud 2009;2:93-106.

3. Vodyanoy V. Characterization of primo nodes and vessels by high resolution light microscopy. In: Soh KS, Kang KA, Harrison DK, eds. The Primo Vascular System: Its Role in Cancer and Regeneration. New York: Springer, 2012:83-94.

4. Vodyanoy V, Pustovyy O, Globa L, Sorokulova I. Primovascular system as presented by Bong Han Kim. Evid Based Complement Alternat Med 2015;2015:361974.

5. Kim BH. Kyungrak System and Theory of Sanal. Bristol: CuriousPages Publishin, 2016.

6. Pawitan JA. Various stem cells in acupuncture meridians and points and their putative roles. J Tradit Complement Med 2018; 8:437-42.

7. Scholkmann F, Shen Y, Ryu PD. Microscopic detection of a red thread-like structure inside primo vessels and primo nodes from the intestine surface of rats. Matters (Zur) 2019. https://doi. org/10.5167/uzh-177094

8. Lim CJ, Yoon YS, Ryu PD. Mesothelial cells covering the surface of primo vascular system tissue. J Acupunct Meridian Stud 2020;13:33-8.

9. Mutsaers SE. Mesothelial cells: their structure, function and role in serosal repair. Respirology 2002;7:171-91.

10. Lim CJ, Lee SY, Ryu PD. Identification of primo-vascular system in abdominal subcutaneous tissue layer of rats. Evid Based Complement Alternat Med 2015;2015:751937.

11. Lee BS, Lee BC, Park JE, Choi HK, Choi SJ, Soh KS. Primo vascular system in human umbilical cord and placenta. J Acupunct Meridian Stud 2014;7:291-7.

12. Jung SJ, Cho SY, Bae KH, Hwang SH, Lee BC, Kim S, et al. Protocol for the observation of the primo vascular system in the lymph vessels of rabbits. J Acupunct Meridian Stud 2012;5:23440.

13. Lee SH, Bae KH, Kim GO, Nam MH, Choi YB, Kwon HM, et al. Primo vascular system in the lymph vessel from the inguinal to the axillary nodes. Evid Based Complement Alternat Med 2013; 2013:472704.
14. Mustafa FEA. Putative primo-vascular system in rabbit pla centa. J Acupunct Meridian Stud 2019;12:20-4.

15. Ogay V, Bae KH, Kim KW, Soh KS. Comparison of the characteristic features of Bonghan ducts, blood and lymphatic capillaries. J Acupunct Meridian Stud 2009;2:107-17.

16. Stefanov M, Potroz M, Kim J, Lim J, Cha R, Nam MH. The primo vascular system as a new anatomical system. J Acupunct Meridian Stud 2013;6:331-8.

17. Kim J, Jung J, Potroz M. Summary of Bong-Han Kim's publications. In: Soh KS, Kang KA, Harrison DK, eds. The Primo Vascular System: Its Role in Cancer and Regeneration. New York: Springer, 2012:7-17.

18. Lim CJ, Yoo JH, Kim Y, Lee SY, Ryu PD. Gross morphological features of the organ surface primo-vascular system revealed by hemacolor staining. Evid Based Complement Alternat Med 2013;2013:350815.

19. Lee HS, Lee JY, Kang DI, Kim SH, Lee I, Park SH, et al. Evidence for the primo vascular system above the epicardia of rat hearts. Evid Based Complement Alternat Med 2013;2013:510461.

20. Cerri PS, Pereira-Júnior JA, Biselli NB, Sasso-Cerri E. Mast cells and MMP-9 in the lamina propria during eruption of rat molars: quantitative and immunohistochemical evaluation. J Anat 2010;217:116-25.

21. Gil H, Bae KH, Kim L, Kim S, Soh KS. Number density of mast cells in the primo nodes of rats. J Acupunct Meridian Stud 2015; 8:288-93.

22. Galli SJ, Borregaard N, Wynn TA. Phenotypic and functional plasticity of cells of innate immunity: macrophages, mast cells and neutrophils. Nat Immunol 2011;12:1035-44.

23. Krystel-Whittemore M, Dileepan KN, Wood JG. Mast cell: a multi-functional master cell. Front Immunol 2016;6:620.

24. Lee BC, Yoo JS, Ogay V, Kim KW, Dobberstein H, Soh KS, et al. Electron microscopic study of novel threadlike structures on the surfaces of mammalian organs. Microsc Res Tech 2007;70:3443.

25. Liao W, Long H, Chang CC, Lu Q. The eosinophil in health and disease: from bench to bedside and back. Clin Rev Allergy Immunol 2016;50:125-39.

26. Bain BJ. Structure and function of red and white blood cells. Medicine (Abingdon) 2017;45:187-93.

27. Territo MC, Cline MJ. Monocyte function in man. J Immunol 1977;118:187-92.

28. Wynn TA, Chawla A, Pollard JW. Macrophage biology in development, homeostasis and disease. Nature 2013;496:445-55.

29. Adkinson NF Jr, Bochner BS, Burks AW, Busse WW, Holgate ST, Lemanske RF Jr, et al. Middleton's Allergy: Principles and Practice, 8th ed. Philadelphia: Elsevier Health Sciences, 2013.

30. Pioli PD. Plasma cells, the next generation: beyond antibody secretion. Front Immunol 2019;10:2768.

31. Lim CJ, Shen Y, Lee SY, Ryu PD. Potential erythropoiesis in the primo-vascular system in heart failure. Adv Exp Med Biol 2017; 
977:409-15

32. Kwon BS, Ha CM, Yu S, Lee BC, Ro JY, Hwang S. Microscopic nodes and ducts inside lymphatics and on the surface of inter nal organs are rich in granulocytes and secretory granules. Cytokine 2012;60:587-92.

33. Soh KS. Current state of research on the primo vascular system. In: Soh KS, Kang KA, Harrison DK, eds. The Primo Vascular System: Its Role in Cancer and Regeneration. New York: Sprin ger, 2012:25-39.

34. Kim J, Ogay V, Lee BC, Kim MS, Lim I, Woo HJ, et al. Catecho lamine-producing novel endocrine organ: Bonghan system. Med Acupunct 2008;20:97-102.

35. Paravati S, Rosani A, Warrington SJ. Physiology, catecholamines. Available at: https://www.ncbi.nlm.nih.gov/books/ NBK507716/ [Date accessed: October 30, 2021]

36. Prokopová I. [Noradrenaline and behavior]. Cesk Fysiol 2010;59: 51-8. Czech.

37. Park ES, Lee JH, Kim WJ, Heo J, Shin DM, Leem CH. Expres sion of stem cell markers in primo vessel of rat. Evid Based Complement Alternat Med 2013;2013:438079.

38. Kang KA, Pustovyy O, Globa L, Sorokulova I, Vodyanoy V. Sanal-cell cycle and primo vascular system: regeneration via sanals. Adv Exp Med Biol 2018;1072:413-8.

39. Ogay V, Soh KS. Identification and characterization of small stem-like cells in the primo vascular system of adult animals. In: Soh KS, Kang KA, Harrison DK, eds. The Primo Vascular System: Its Role in Cancer and Regeneration. New York: Sprin ger, 2012:149-55.

40. Shin HS, Johng HM, Lee BC, Cho SI, Soh KS, Baik KY, et al. Feulgen reaction study of novel threadlike structures (Bonghan ducts) on the surfaces of mammalian organs. Anat Rec B New Anat 2005;284:35-40.

41. Jang H, Yoon J, Gil H, Jung SJ, Kim MS, Lee JK, et al. Obser vation of a flowing duct in the abdominal wall by using nano particles. PLoS One 2016;11:e0150423.

42. Cha $\mathrm{Y}$, Choe $\mathrm{H}$, Oh S, Cha Z. The primo vascular system is the substance of meridians. Research Square [Preprint]. 2020 Available from: https://web.archive.org/web/20200821100527id_ /https://assets.researchsquare.com/files/rs-55227/v1/d35ccc55bd9f-4e4d-a556-abcae39d5f19.pdf.

43. Qureshi NA, Alkhamees OA, Alsanad SM. Cupping therapy (Al-Hijamah) points: a powerful standardization tool for cupping procedures? J Complement Altern Med Res 2018;4:1-13.

44. Yonghong S, Ruizhi W, Yue Z, Xuebing B, Tarique I, Chunhua $\mathrm{L}$, et al. Telocytes in different organs of vertebrates: potential essence cells of the meridian in Chinese traditional medicine. Microsc Microanal 2020;26:575-88.

45. Varga I, Polák Š, Kyselovič J, Kachlík D, Danišovič L, Klein M. Recently discovered interstitial cell population of telocytes: distinguishing facts from fiction regarding their role in the pathogenesis of diverse diseases called "telocytopathies". Medi cina (Kaunas) 2019;55:56.

46. Mustafa FEA, Elhanbaly R. Distribution of estrogen receptor in the rabbit cervix during pregnancy with special reference to stromal elements: an immunohistochemical study. Sci Rep 2020;10:13655.

47. Abd-Elhafeez HH, Hassan AHS, Hussein MT. Melatonin administration provokes the activity of dendritic reticular cells in the seminal vesicle of Soay ram during the non-breeding season. Sci Rep 2021;11:872.

48. Mustafa FEA, El-Desoky SMM. Architecture and cellular com position of the spleen in the Japanese quail (Coturnix japonica). Microsc Microanal 2020;26:589-98.

49. Mustafa FEA, Elhanbaly R. Histological, histochemical, immunohistochemical and ultrastructural characterization of the testes of the dove. Zygote 2021;29:33-41.

50. Abd-Elhafeez HH, Soliman SA. New description of telocyte sheaths in the bovine uterine tube: an immunohistochemical and scanning microscopic study. Cells Tissues Organs 2017;203: 295-315.

51. Abdel-Maksoud FM, Abd-Elhafeez HH, Soliman SA. Morpho logical changes of telocytes in camel efferent ductules in response to seasonal variations during the reproductive cycle. Sci Rep 2019;9:4507.

52. Abd-Elhafeez HH, Abou-Elhamd AS, Soliman SA. Morpho logical and immunohistochemical phenotype of TCs in the intestinal bulb of Grass carp and their potential role in intesti nal immunity. Sci Rep 2020;10:14039. Erratum in: Sci Rep 2021; 11:11853.

53. Soliman SA. Telocytes are major constituents of the angiogenic apparatus. Sci Rep 2021;11:5775.

54. Soliman SA, Madkour FA. Developmental events and cellular changes occurred during esophageal development of quail embryos. Sci Rep 2021;11:7257.

55. Soliman SA. Telocytes during nephrogenesis: relations to ne phrogenic cords in mesonephros of quail embryos. Histol Cytol Embryol 2017;1:1-6.

56. Mustafa FEA, Abdelhafez EA, Abd-Elhafeez HH. Characteri zation of the primo vascular system in rabbit vagina. Microsc Res Tech 2022;85:799-806.

57. Chikly B, Roberts P, Quaghebeur J. Primo vascular system: a unique biological system shifting a medical paradigm. J Am Osteopath Assoc 2016;116:12-21. Erratum in: J Am Osteopath Assoc 2016;116:201.

58. Yoo JS, Kim HB, Ogay V, Lee BC, Ahn S, Soh KS. Bonghan ducts as possible pathways for cancer metastasis. J Acupunct Meridian Stud 2009;2:118-23.

59. Yoo JS, Kim HB, Won N, Bang J, Kim S, Ahn S, et al. Evidence for an additional metastatic route: in vivo imaging of cancer cells in the primo-vascular system around tumors and organs. Mol Imaging Biol 2011;13:471-80.

60. Islam MA, Thomas SD, Sedoris KJ, Slone SP, Alatassi H, Miller 
DM. Tumor-associated primo vascular system is derived from xenograft, not host. Exp Mol Pathol 2013;94:84-90.

61. Kang KA, Maldonado C, Perez-Aradia G, An P, Soh KS. Primo vascular system and its potential role in cancer metastasis. Adv Exp Med Biol 2013;789:289-96.
62. Heo C, Hong MY, Jo A, Lee YH, Suh M. Study of the primo vascular system utilizing a melanoma tumor model in a green fluorescence protein expressing mouse. J Acupunct Meridian Stud 2011;4:198-202. 